\title{
In Vitro Effects of Mesenchymal Stem Cells and Various Agents on Apoptosis of Glioblastoma Cells
}

\author{
Bahattin TANRIKULU1', Ibrahim ZIYAL ${ }^{2}$, Yasar BAYRI ${ }^{2}$ \\ ${ }^{1}$ Acıbadem Mehmet Ali Aydınlar University, School of Medicine, Department of Neurosurgery, Division of Pediatric Neurosurgery, \\ Istanbul, Turkey \\ ${ }^{2}$ Marmara University, School of Medicine, Department of Neurosurgery, Istanbul, Turkey
}

\section{ABSTRACT}

AIM: To investigate a new anti-tumor treatment method using stem cells transfected with specific genes and proteins that induce apoptosis in tumor cells.

MATERIAL and METHODS: We used glioblastoma (GBM) cells and human adipose tissue-derived mesenchymal stem cells (ADMSCs) in this study. The AD-MSCs were transfected with the tumor necrosis factor-related apoptosis-inducing ligand (TRAIL). To overcome apoptosis resistance in tumor cells, we used suberoylanilide hydroxamic acid (SAHA) as the histone deacetylase inhibitor and embelin as the X-linked inhibitor of apoptosis protein (XIAP). In addition, we silenced the XIAP gene on GBM cells with the shXIAP plasmid. Following the determination of half-maximal effective concentration (EC50\%) doses of SAHA and embelin, GBM cells were incubated with them for 24 hours. XIAP-silenced and XIAP-non-silenced GBM cells were cultured with TRAIL-nontransfected and TRAIL-transfected stem cells for 24 hours. Viability and cell cycle analysis of all groups were determined using annexin V/propidium iodide and cell cycle method via flow cytometry.

RESULTS: TRAIL-transfected AD-MSCs, XIAP silencing, embelin, and SAHA induced apoptosis in GBM cells and decreased their proliferation, whereas TRAIL-non-tranfected AD-MSCs did not.

CONCLUSION: Engineered stem cell therapies and molecular studies show promise in developing combination therapies for effective treatment of GBM.

KEYWORDS: Embelin, Glioblastoma, Mesenchymal stem cell, SAHA, TRAIL

\section{INTRODUCTION}

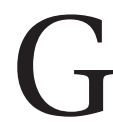
lioblastoma (GBM) is a World Health Organization (WHO) grade IV astrocytoma (9). It is the most common and most aggressive primary brain tumor, accounting for approximately $60 \%-75 \%$ of all astrocytomas and $12 \%-15 \%$ of all intracranial tumors (27). The current treatment protocol for GBM is maximal safe surgical resection, radiotherapy, and chemotherapy (48). Despite this aggressive medical strategy, GBMs are either refractory or resistant to treatment (44). Even if gross total resection is confirmed by magnetic resonance imaging, local GBM recurrences are common because of microscopic tumor infiltration along perivascular spaces and white matter tracts (11). Recurrence has also been attributed to genetic heterogeneity and the complex molecular pathology of GBM $(20,29)$. Unfortunately, most systemic chemotherapeutics developed to treat GBM are ineffective because of their inability to cross the blood-brain barrier at certain doses without exerting systemic toxicity (31). Therefore, the treatment of malignant gliomas is one of the most difficult challenges in neuro-oncology. Recently, inspiring studies have found that targeted therapy that acts on specific signaling pathways that underlie uncontrolled cellular growth and induce apoptosis might be an effective and practical option for GBM treatment (13). Studies have also found that stem cells have tumor-specific homing properties and that programming 
them with genetic engineering to carry and release anti-tumor proteins that induce apoptosis is effective in in vitro and in vivo models of GBM cells $(2,15,18,32,37,39,40)$.

Apoptosis is a physiologic, programmed cell death process that helps regulate homeostasis and is triggered by the activation of intracellular death program (34). One of the wellknown tumor-specific proteins that induce apoptosis is tumor necrosis factor-related apoptosis-inducing ligand (TRAIL). It exerts apoptotic effects via death receptors 4 and 5 in a wide variety of glioma cell lines, including intracranial human GBM xenografts in mice $(2,35,40)$. Previous studies have shown that on-site delivery of TRAIL via stem cells has more anti-tumoral effects than administration of TRAIL alone $(17,35)$. However, GBM cells might display resistance to apoptosis by increasing the synthesis of survival proteins or decreasing the synthesis of pro-apoptotic ones $(36,43)$. One of the well-known proteins responsible for TRAIL-induced apoptosis resistance is the X-linked inhibitor of apoptosis protein (XIAP). It has been found that XIAP concentration is high in cancer cells that exhibit resistance to TRAIL-induced apoptosis $(1,24)$.

Embelin is a small herbal molecule derived from Embelia ribes. Interestingly, embelin, which exerts anti-tumoral effects for different types of tumors by inhibiting XIAP, has no inhibitory effect on XIAP in GBM cells. Its anti-tumoral effect in GBM cells is via inhibition of different anti-apoptotic pathways (30). Another way of inhibiting apoptosis in different types of human tumors, including GBM $(45,46)$, is by inhibiting some tumor suppressor genes via deacetylation by histone deacetylase (45). Histone acetylation-deacetylation is an important regulator of gene expression in normal and cancer cells (47). Suberoylanilide hydroxamic acid (SAHA) is a histone deacetylase inhibitor and has been demonstrated to slow the proliferation of GBM cells (46).

Additionally, the presence of GBM stem cells, which are a highly tumorigenic subpopulation of cancer cells extremely resistant to chemotherapy and radiotherapy, is said to be responsible for apoptotic resistance in GBM $(22,42)$. Therefore, investigations for developing novel therapeutic regimens to cure GBM should focus on apoptotic resistance in both GBM cells and GBM stem cells (13).

In this in vitro study, we identified that mesenchymal stem cells (MSCs) may be used as a "Trojan horse" to carry an "assassin team" (TRAIL) to the target (GBM cells). We also identified that a combination of embelin, SAHA, and XIAP silencing potentiates the pro-apoptotic effects of TRAIL.

\section{MATERIAL and METHODS}

This study was approved by the Marmara University Local Ethical Council of Experimental Research on December 2, 2013 ( 45.2013.mar).

\section{Cell Culture}

Human U251 GBM cells (purchased from ATCC with the catalog number CRL-1690) were cultured in Dulbecco's Modified Eagle's Medium (DMEM) supplemented with $100 \mathrm{U} /$ $\mathrm{mL}$ penicillin and $100 \mathrm{U} / \mathrm{mL}$ streptomycin in a humidified atmosphere of $5 \% \mathrm{CO}_{2}$ and $95 \%$ air at $37^{\circ} \mathrm{C}$.

\section{Cell Passaging}

After GBM cells became confluent, covering approximately $70 \%-80 \%$ of the flask surface area, they were transferred to another flask. The growth medium was changed every 3 or 4 days on the basis of $\mathrm{pH}$ changes. The cells were frozen with $90 \%$ fetal bovine serum (FBS) and 10\% dimethylsulfoxide.

\section{Cell Counting}

The GBM cells in the flask were washed out from the growth medium with sterile phosphate-buffered saline (PBS). Trypsin/ ethylenediaminetetraacetic acid, preheated to $37^{\circ} \mathrm{C}$, was added to the flask $\left(0.5 \mathrm{~mL}\right.$ for a $25 \mathrm{~cm}^{2}$ flask area; $1.5 \mathrm{~mL}$ for a $75 \mathrm{~cm}^{2}$ flask area). The flask was stored in an incubator for 4-5 min. The cells taken from the flask's surface were put in $15 \mathrm{~mL}$ tubes. Next, $5 \mathrm{~mL}$ of FBS growth medium was added to each tube, and the tubes were centrifuged at $1300 \mathrm{rpm}$ for $5 \mathrm{~min}$. The supernatant was taken out of each tube, and the pellets were suspended in the growth medium. A $10 \mu \mathrm{L}$ cell suspension was mixed with $10 \mu \mathrm{L}$ trypan blue, and $10 \mu \mathrm{L}$ of the suspension was put in a Thoma counting chamber. The cells were counted under a phase-contrast light microscope. The blue-stained cells were considered dead, whereas cells not stained with trypan blue were considered alive. The cell count in $1 \mathrm{~mL}$ of one cell suspension was calculated using the following formula:

$$
\begin{gathered}
\text { Cell count } / \mathrm{mL}=\text { Mean count value (no. of cells in } 64 \\
\text { squares } / 4 \text { ) } \times \text { Dilution factor } \times 10^{4}
\end{gathered}
$$

The cells were also counted using a Casy cell counter. A $10 \mu \mathrm{L}$ suspended GBM cell sample was mixed with $10 \mathrm{~mL}$ Casy tone liquid and analyzed. The count of cells that were dead and alive was noted.

\section{Determining the Inhibitory Concentration $\left(\mathrm{IC}_{50}\right)$ of Embelin and SAHA}

The cytotoxicity of embelin and SAHA on GBM cells was determined by the WST-1 cell proliferation test. GBM cells were seeded in a 96-well plate in triplicate fashion. There were $5 \times 10^{3}$ cells in each well. The cells were incubated for 24 hours to let them adhere to the wells. Predetermined amounts of embelin and SAHA were added to the wells separately. After 24 hours, $10 \mu \mathrm{L}$ WST-1 solution was added to the wells. After a 4-hour incubation period, absorbance measurement was performed via a microplate absorbance reader.

\section{Plasmids and Reagents}

A plasmid vector expressing a fusion protein consisting of a green fluorescent protein (GFP) and the full length of human TRAIL (pEGFP-TRAIL) was bought from Addgene (plasmid \#10953)(17). This plasmid contains kanamycin as a bacterial resistance gene and neomycin as an identification marker. The bacterial culture was incubated overnight at $37^{\circ} \mathrm{C}$ in Luria broth (LB) growth medium, which also contained $100 \mu \mathrm{g} / \mathrm{mL}$ kanamycin. On the next day, plasmid isolation was performed with a High Pure Plasmid Isolation Kit (Roche catalog no. 11754777001). The isolated plasmid was confirmed by a double-cut procedure with Bam I and EcoRI (Fermentas) restriction enzymes. 
We used the shXIAP plasmid (Qiagen, SureSilencing, catalog no. $336311 \mathrm{KH00323G)}$ for XIAP silencing. Inside the kit were four different XIAP sites and one negative control, and this plasmid had an ampicillin-resistant gene. The plasmid was transferred into Escherichia coli (E. coli) via transformation. For transformation, we first prepared competent cells via the $\mathrm{CaCl}_{2}$ method. One $0.5 \mathrm{~mL}$ E. coli culture was added to $50 \mathrm{~mL}$ LB growth medium and centrifuged at $37^{\circ} \mathrm{C}$ at $180 \mathrm{rpm}$ until the optical density of $E$. coli reached $0.6\left(4.8 \times 10^{8} \mathrm{cells} / \mathrm{mL}\right)$. The bacterial culture was put into an ice solution for 10 minutes and then centrifuged at $4^{\circ} \mathrm{C}$ at $14,000 \mathrm{rpm}$ for 4 minutes. Then, $10 \mathrm{~mL} \mathrm{CaCl}$, was added over the pellet and left in ice for 30 minutes. The solution was re-centrifuged at $4^{\circ} \mathrm{C}$ at $14,000 \mathrm{rpm}$ for 4 minutes. The pellet was suspended in $2 \mathrm{~mL}$ $0.1 \mathrm{M} \mathrm{CaCl}_{2}$ solution and stored at $4^{\circ} \mathrm{C}$. For transformation; we took one vial of competent $E$. coli (BL-21 strain), which was stored at $-80^{\circ} \mathrm{C}$ and was held in ice for 15 minutes. Then, half of the vial $(100 \mu \mathrm{L})$ was put in a $1.5 \mathrm{~mL}$ tube, and the remaining half was stored as the control group. Two $2 \mu \mathrm{L}$ shXIAP plasmids were mixed with $E$. coli in the tube, which was placed on ice for 30 minutes, then kept at $42^{\circ} \mathrm{C}$ for 90 seconds, and again placed on ice for 5 minutes. Next, $900 \mu \mathrm{L}$ LB growth medium was added and shaken via a vortex at $300 \mathrm{rpm}$ at $37^{\circ} \mathrm{C}$. After 80 -minute incubation at $37^{\circ} \mathrm{C}$, the mixture was centrifuged at $4500 \mathrm{rpm}$ for 10 minutes. The pellet was mixed with $100 \mu \mathrm{L}$ LB growth medium and cultivated on an ampicillin-containing LB petri dish. The petri dish was incubated at $37^{\circ} \mathrm{C}$ overnight. After incubation, one colony was chosen from the petri dish and cultivated in LB growth medium containing $100 \mu \mathrm{g} / \mathrm{mL}$ ampicillin. The next day, plasmid isolation was performed with a High Pure Plasmid Isolation Kit (Roche catalog no. 11754777001). The entire procedure was repeated for four different XIAP regions.

Pstl enzyme (Fermentas catalog no. ER0611) was used for plasmid confirmation because the plasmid had a Pstl enzyme cleavage site. For this procedure, $5 \mu \mathrm{L}$ plasmid DNA (mass was $1 \mu \mathrm{g}$ or more), $2 \mu \mathrm{L} 10 \mathrm{X}$ Buffer O, $1 \mu \mathrm{L}$ Pstl cleavage enzyme, $10 \mu \mathrm{L}$ DNAse, and RNAse-free water were mixed in a tube. The mixture was incubated at $37^{\circ} \mathrm{C}$ for 45 minutes and then monitored with $1 \%$ agarose gel electrophoresis at $100 \mathrm{~V}$ for 40 minutes.

\section{Transfection of pEGFP-TRAIL Vector into Adipose Tissue- Derived MSCs and Fibroblasts with Electroporation}

Transfection of the pEGFP-TRAIL plasmid vector to human adipose tissue-derived MSCs (AD-MSCs) and fibroblasts was performed with an Amaxa Nucleofector machine. Cells were grown in a culture plate, trypsinized, and stored. We prepared $1 \times 10^{6}$ cells for each well and put them in $100 \mu \mathrm{L}$ nucleofector solutions. Then, $1.5 \mu \mathrm{g}$ of plasmids was added, and all mixtures were transferred to cuvettes. Cuvettes were placed in the nucleofector machine and transfected via the FF-104 program. After transfection, a growth medium was added over the cuvettes and cells were put in 24-well plates.

\section{Transfection of the shXIAP Plasmid into GBM Cells}

For each well, $5 \times 10^{5} \mathrm{GBM}$ cells were placed in 24-well plates, which contained DMEM. Transfection was done after the GBM cells covered $60 \%-70 \%$ of the surface. Lipofectamine 2000 (Invitrogen) transfection solution was used for transfection. The procedure was performed by using 24-well plate ratios as per manufacturer's instructions. Plasmid DNA $(0.8 \mu \mathrm{g})$ was diluted in $50 \mu \mathrm{L}$ serum-free DMEM, and $2 \mu \mathrm{L}$ transfection solution was diluted in $50 \mu \mathrm{L}$ serum-free DMEM and kept at room temperature for 5 minutes. Both mixtures were combined together and kept at room temperature for 20 minutes. Then, the $100 \mu \mathrm{L}$ mixture was slowly added to the wells. The cells were incubated at $37^{\circ} \mathrm{C}$ in a humidified atmosphere of $5 \%$ $\mathrm{CO}_{2}$ and $95 \%$ air. Every 4-6 hour, the growth medium of the cells was replaced, and after a 24-hour incubation period, transfection of shXIAP was confirmed under a fluorescence microscope.

\section{Choosing the Most Effective XIAP-Silencing Region in GBM Cells}

The shXIAP plasmid (Qiagen) had four different regions that act on different sites of the target gene for silencing. These regions were applied to the cells one by one. The region that was most effective for XIAP silencing was chosen for ongoing experiments. Gene expressions were tested via real-time polymerase chain reaction (RT-PCR). After transfection into the cells, RNAs were isolated from the cells via the RNeasy Mini RNA isolation kit (Qiagen, catalog no. 74104). Complementary DNAs (cDNAs) were synthesized from RNAs by using the Strand cDNA Synthesis Kit (Fermentas, catalog no. K1652).

\section{Co-culture of Human AD-MSCs and GBM Cells}

GBM cells with an active gene and an inactive XIAP gene were put in 6-well plates with DMEM. Each well contained $1 \times 10^{6}$ cells. The cells were incubated in a humidified atmosphere of $5 \% \mathrm{CO}_{2}$ and $95 \%$ air at $37^{\circ} \mathrm{C}$. After incubation for 24 hours, the GBM cells were put into 0.4-inch-diameter pore-sized cell culture inserts (BD-353090). TRAIL-transfected and TRAILnontransfected human AD-MSCs and fibroblasts were added to the inserts. The cells were incubated at $37^{\circ} \mathrm{C}$ in a humidified atmosphere of $5 \% \mathrm{CO}_{2}$ and $95 \%$ air.

Our experimental groups were as follows:

- Group 1 (Control group): GBM cells and fibroblasts were co-cultured.

- Group 2: GBM cells and human AD-MSCs were cocultured.

- Group 3: GBM cells and TRAIL-transfected human ADMSCs were co-cultured.

- Group 4: GBM cells and TRAIL-transfected human ADMSCs were co-cultured, and embelin was added to the medium.

- Group 5: GBM cells and TRAIL-transfected human ADMSCs were co-cultured, and SAHA was added to the medium.

- Group 6: XIAP-silenced GBM cells and TRAIL-transfected human AD-MSCs were co-cultured, and embelin and SAHA were added to the medium. 


\section{Annexin V/PI Assay}

Next, $2 \mathrm{~mL}$ of $5 \times 10^{5}$ cells were put in 6 -well plates and incubated at $37^{\circ} \mathrm{C}$ for 24 hours in a humidified atmosphere of $5 \% \mathrm{CO}_{2}$ and $95 \%$ air. The experimental groups were organized and incubated as previously described. The content of each well was poured into a different tube and used for the annexin V/propidium iodide (PI) apoptosis assay and cell cycle regulation analysis. The cell suspensions for the annexin $\mathrm{V} / \mathrm{PI}$ assay were centrifuged at $1300 \mathrm{rpm}$ for 5 minutes. Each pellet was suspended with $115 \mu \mathrm{L}$ of a florescent reactive. The tubes were incubated in the dark for 15 minutes, and then $400 \mu \mathrm{L}$ PBS was added to each tube. The cell suspension in each tube was analyzed by a flow cytometer with FL1 and FL2 filters. The results were used for statistical analysis.

\section{Statistical Analysis}

The outputs were analyzed with one-way analysis of variance in GP Prism5-GraphPad Software (San Diego, CA, USA, 2007) and reported as a mean standard deviation.

\section{RESULTS}

\section{IC $_{50}$ of Embelin and SAHA}

The $\mathrm{IC}_{50}$ values of embelin and SAHA on human U251 GBM cells were found to be 75 and $3 \mu \mathrm{M}$, respectively (Figures $1,2)$. The embelin and SAHA fraction-affected values were calculated using the CalcuSyn software as 50 and $1.5 \mu \mathrm{M}$, respectively.

\section{Confirmation of shXIAP Transfection under a Fluorescence Microscope and Determination of the Most Effective XIAP- Silencing Region on GBM Cells}

Under a fluorescence microscope, the GFP confirmed the transfection of the shXIAP plasmid into GBM cells (Figure 3). The most effective XIAP-silencing region on GBM cells was determined with RT-PCR. The most effective gene silencing was observed on the $\mathrm{C} 2$ region (Figure 4). With these findings, we continued our experiments with XIAP clone 2.

\section{Determination of Apoptosis with Annexin V/PI Assay via Flow Cytometry}

The annexin V/PI assay was performed for all experimental groups. For each step, $10^{5}$ cells were counted. The GBM cells that were alive were annexin $\mathrm{V}$ negative and PI negative; the early apoptotic GBM cells were annexin V positive and PI negative; the late apoptotic GBM cells were annexin $V$ positive and PI positive; and the necrotic GBM cells were annexin V negative and $\mathrm{PI}$ positive. The percentage of GBM cells in each category (alive, early apoptotic, late apoptotic, and necrotic) was calculated for all experimental groups. The sum of the percentages of early and late apoptotic GBM cells in each experimental group was accepted as the percentage of the total apoptotic GBM cells for that experimental group. The percentage of apoptosis in each group is depicted in a bar chart in Figure 5.

Compared with the control group, no statistically significant increase in apoptosis was observed in the GBM/AD-MSC group ( $p>0.05$ ). There was a statistically significant increase in apoptosis in the GBM/TRAIL+AD-MSC group, the GBM/ TRAIL+AD-MSC+embelin group, the GBM/TRAIL+AD$\mathrm{MSC}+\mathrm{SAHA}$ group, and the XIAP-GBM/TRAIL+AD-MSC+ embelin+SAHA group in comparison with the control group $(p<0.05)$. The most effective apoptosis was observed in

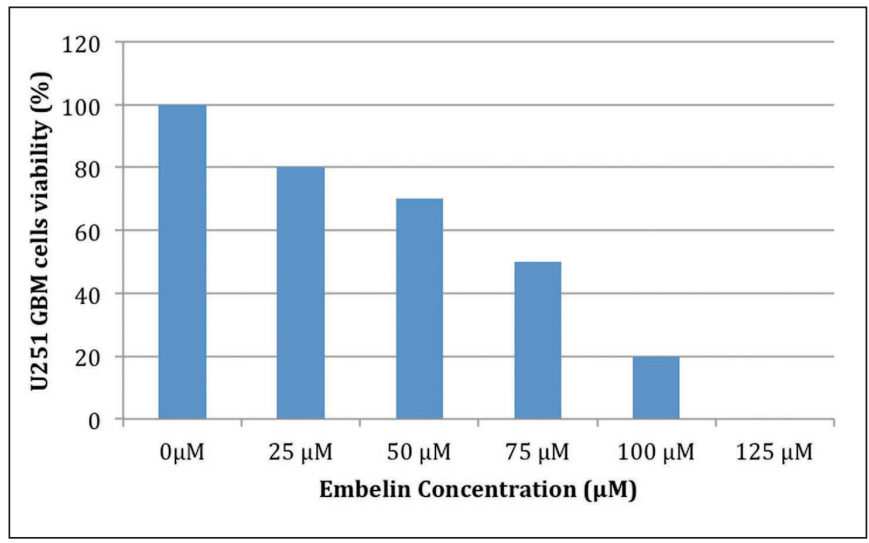

Figure 1: $\mathrm{EC}_{50}$ value of embelin.

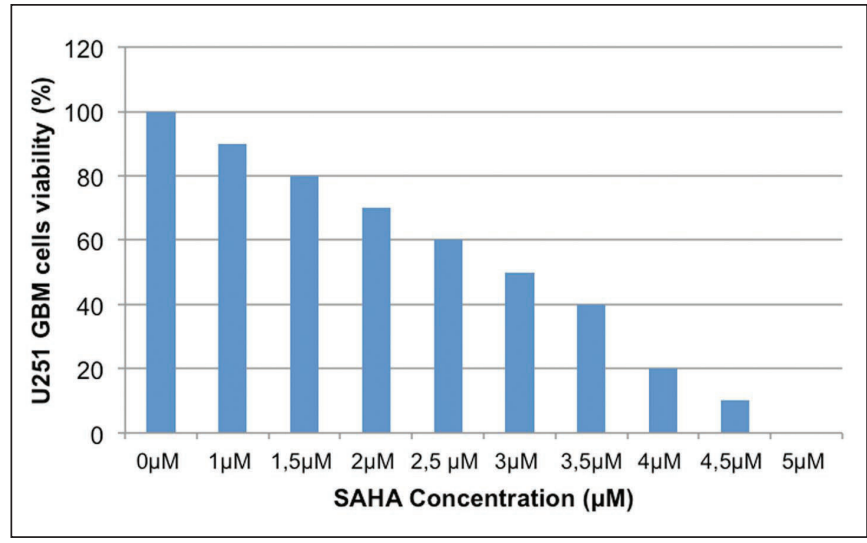

Figure 2: $\mathrm{EC}_{50}$ value of SAHA.

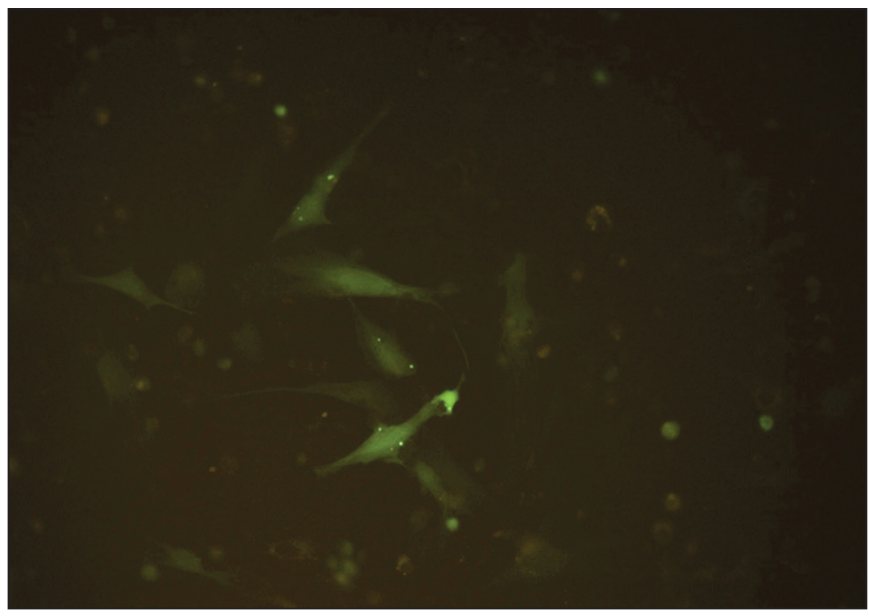

Figure 3: Green fluorescence illumination under a fluorescence microscope confirms the shXIAP plasmid transfection of GBM cells. 
Tanrikulu B. et al: Induced Apoptosis of GBM Cells

the GBM/TRAIL+AD-MSC+embelin+SAHA+XIAP-silencing group, and the apoptosis rate was significantly higher than that of any other experimental group in the study $(p<0.05)$.

\section{DISCUSSION}

This study was performed to evaluate the effects of MSCs, TRAIL, XIAP silencing, embelin, and SAHA on the apoptosis of human U251 GBM cells.

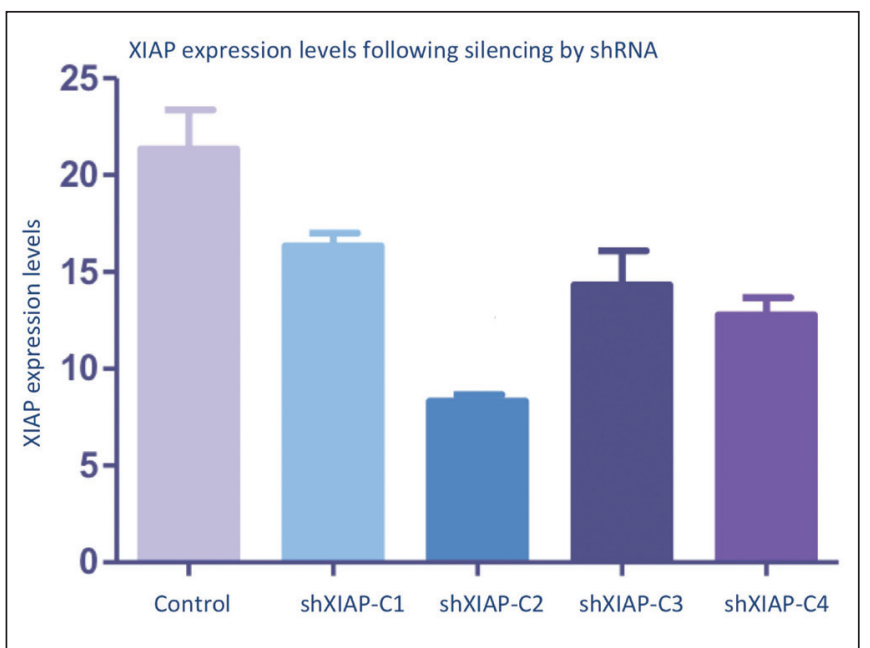

Figure 4: The most effective XIAP-silencing region on GBM cells was determined with RT-PCR. The most effective gene silencing was observed on the $\mathrm{C} 2$ region.

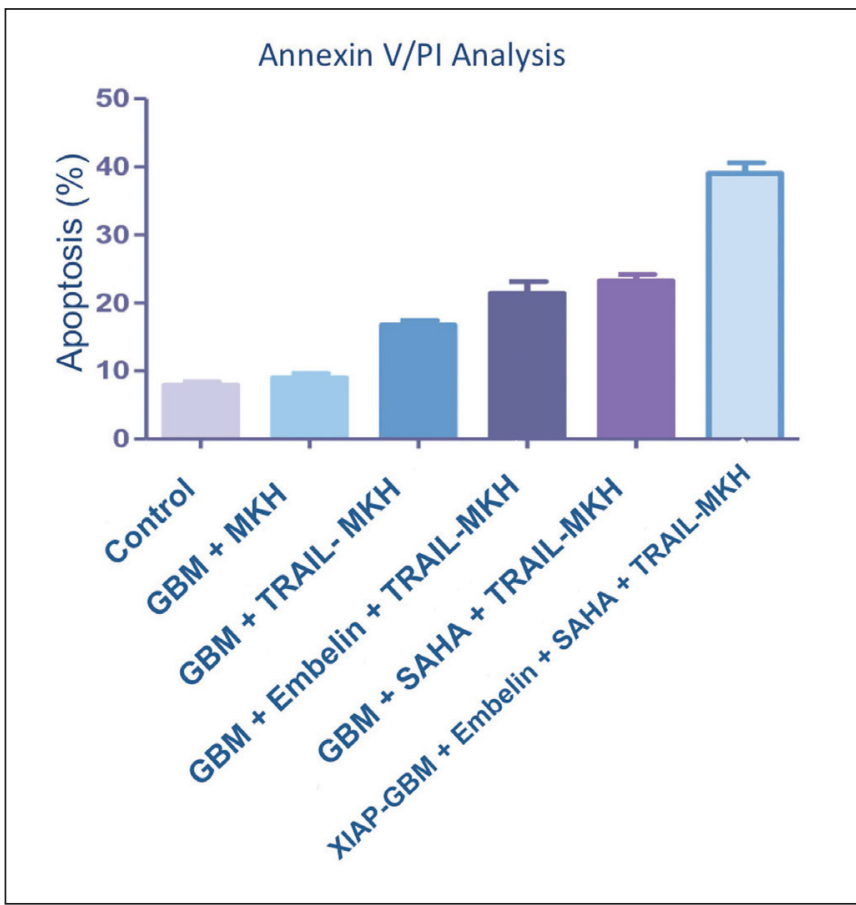

Figure 5: Bar chart showing the percentage of apoptosis in each experimental group. The highest apoptosis was observed in the GBM/TRAIL-AD-MSC+embelin+SAHA+XIAP-silencing group.
A variety of cancer-related molecular alterations have been identified in recent years. Some of these alterations are supposed to be potential targets for GBM treatment. One of the new and promising experimental treatment strategies for GBM is the re-activation of TRAIL-induced apoptosis. TRAIL is responsible for normal homeostasis, immune surveillance, determination of self/non-self-cells, immunomodulation, and elimination of virally infected cells and cancer cells $(14,16,21)$.

TRAIL-induced apoptosis seems to be an excellent anticancer treatment strategy for GBM because TRAIL selectively induces apoptosis in tumor cells, sparing normal cells $(6,28,33)$. Recent studies have shown that sustained levels of TRAIL are needed for effective TRAIL-induced apoptosis in cancer treatment (18). Most studies investigating TRAIL-induced apoptosis for cancer treatment have used human or mouse MSCs for sustained synthesis and release of TRAIL to the tumor microenvironment $(3,8,10,18,23,37,38)$. In this study, we used human AD-MSCs for TRAIL synthesis and secretion.

TRAIL is an effective antitumor agent, but nearly more than $50 \%$ of GBM lines are resistant to TRAIL-induced apoptosis $(18,28,33)$. Therefore, identification of survival signals that help GBM cells escape from TRAIL-induced apoptosis is crucial for designing TRAIL-associated combination regimens for GBM treatment. Overexpression of proteins that inhibit apoptosis is one of the most blamed mechanisms that induce TRAIL resistance in GBM cells. Most of these proteins belong to a family called the inhibitor of apoptosis protein (IAP) family. Griffith et al. and $\mathrm{Ng}$ et al. reported that two members of the IAP family, survivin and XIAP, are responsible for TRAIL-induced apoptosis resistance in certain cancer cells $(12,25)$. These two proteins inhibit apoptosis by interfering with the activities of caspases 3 and 7 (7). Both proteins are overexpressed in GBMs, and their high expressions correlate with a decreased survival rate, increased recurrence, and increased resistance to therapy $(4,19)$. In this study, we blocked XIAP synthesis by shXIAP-silencing of the XIAP gene in GBM cells. This led to a dramatic increase in the apoptosis of GBM cells in comparison with XIAP-expressing groups.

During discussions of XIAP silencing to overcome resistance to TRAIL-induced apoptosis, a new XIAP inhibitor molecule called embelin was discovered. Embelin is extracted from the fruit of $E$. ribes, and has anti-inflammatory, analgesic, and anti-tumor properties. It induces apoptosis in different types of human cancer cells by inhibiting NF-kB, STAT3, peroxisome proliferator-activated receptor gamma, and XIAP $(5,26,30)$. Siegelin et al. showed that embelin enhanced TRAIL-induced apoptosis in human U251 and LN229 glioma cells by reducing the expression of cellular FLICE-like inhibitory protein (41). Park et al. showed that embelin exerts pro-apoptotic effects in GBM cells by inhibiting the NF-kB pathway, not the XIAP pathway (30). In this study, addition of embelin into TRAILtransfected AD-MSCs and GBM co-culture media resulted in a statistically significant increase in the apoptosis of GBM cells.

We also tested the effects of SAHA, a histone deacetylase inhibitor, on the apoptosis of GBM cells. Yin et al. showed that SAHA inhibited the growth of GBM cells, with accumulation 
in the G2-M checkpoint. SAHA equally inhibited the growth of both p53 mutant and p53 wild-type glioma cells (46). This result showed that in GBM cells, the anti-proliferative effect of SAHA is independent of p53 activity. In our study, addition of SAHA into TRAIL-transfected AD-MSCs and GBM co-culture media resulted in a statistically significant increase in the apoptosis of GBM cells.

In this in vitro study, we also found that AD-MSCs by themselves have no statistically significant effect on the apoptosis of GBM cells. But the production and secretion of TRAIL by genetically engineered, TRAIL-plasmid-transfected AD-MSCs resulted in a dramatic increase in the apoptosis of GBM cells. Addition of embelin to one co-culture medium of TRAIL/AD-MSCs and addition of SAHA to another co-culture medium of TRAIL/AD-MSCs resulted in increased apoptosis of GBM cells. However, there was no significant difference in apoptosis between both groups. Finally, we saw a second dramatic increase in apoptosis in a combination of all groups including XIAP silencing.

\section{CONCLUSION}

Our study demonstrated the effects of TRAIL-transfected ADMSCs, embelin, SAHA, and XIAP silencing on the apoptosis of GBM cells. We observed the maximum apoptosis in the GBM/ TRAIL/AD-MSCs+embelin+SAHA+XIAP-silencing group.

These results are promising for future combination therapies for GBM. Using this study as a template, new in vivo studies can be planned and novel engineered stem cell transplantation therapies in combination with other anti-cancer agents can be developed for GBM patients.

\section{ACKNOWLEDGMENT}

We would like to thank to BAPKO (Marmara University Scientific Investigation Financial Support Department) for financial support of this study. We also would like to thank to Genetic and Metabolic Disease Research and Investigation Center of Marmara University, and its respectful staff Assoc. Prof. Betul Karademir and postdoctoral fellow Ceyda Corek for the precision and safety of all experimental steps of this study. We also would like to thank Prof. Yavuz Taga for his great work to establish a well equipped research laboratory at Marmara University, School of Medicine, Department of Biochemistry, where this research was performed. He was so openminded mentor for young researchers and supplied all of them with contemporary research ideas. He was the man who paved the road for our research and other forthcoming researches. Rest in piece.

Preparation for publication of this article is partly supported by Turkish Neurosurgical Society.

\section{REFERENCES}

1. Allensworth JL, Aird KM, Aldrich AJ, Batinic-Haberle I, Devi GR: XIAP inhibition and generation of reactive oxygen species enhances TRAIL sensitivity in inflammatory breast cancer cells. Mol Cancer Ther 11:1518-1527, 2012
2. Bagci-Onder $T$, Wakimoto $H$, Anderegg $M$, Cameron $C$, Shah $\mathrm{K}$ : A dual PI3K/mTOR inhibitor, PI-103, cooperates with stem cell-delivered TRAIL in experimental glioma models. Cancer Res 71: 154-163, 2011

3. Balyasnikova IV, Ferguson SD, Han Y, Liu F, Lesniak MS: Therapeutic effect of neural stem cells expressing TRAIL and bortezomib in mice with glioma xenografts. Cancer Lett 310: 148-159, 2011

4. Chakravarti A, Zhai GG, Zhang M, Malhotra R, Latham DE, Delaney MA, Robe P, Nestler U, Song Q, Loeffler J: Survivin enhances radiation resistance in primary human glioblastoma cells via caspase-independent mechanisms. Oncogene 23: 7494-7506, 2004

5. Chitra M, Sukumar E, Suja V, Devi CS: Antitumor, antiinflammatory and analgesic property of embelin, a plant product. Chemotherapy 40: 109-113, 1994

6. Corsten MF, Shah K: Therapeutic stem-cells for cancer treatment: Hopes and hurdles in tactical warfare. Lancet Oncol 9: 376-384, 2008

7. Deveraux QL, Reed JC: IAP family proteins-suppressors of apoptosis. Genes Dev 13: 239-252, 1999

8. Ehtesham M, Kabos P, Gutierrez MA, Chung NH, Griffith TS, Black KL, Yu JS: Induction of glioblastoma apoptosis using neural stem cell-mediated delivery of tumor necrosis factorrelated apoptosis-inducing ligand. Cancer Res 62:7170-7174, 2002

9. Fuller GN: The WHO Classification of Tumours of the Central Nervous System, 4th ed. Arch Pathol Lab Med 132: 906, 2008

10. Germano IM, Uzzaman M, Benveniste RJ, Zaurova M, Keller G: Apoptosis in human glioblastoma cells produced using embryonic stem cell-derived astrocytes expressing tumor necrosis factor-related apoptosis-inducing ligand. J Neurosurg 105: 88-95, 2006

11. Giese A, Bjerkvig R, Berens ME, Westphal M: Cost of migration: Invasion of malignant gliomas and implications for treatment. J Clin Oncol 21:1624-1636, 2003

12. Griffith TS, Fialkov JM, Scott DL, Azuhata T, Williams RD, Wall NR, Altieri DC, Sandler AD: Induction and regulation of tumor necrosis factor-related apoptosis-inducing ligand/Apo2 ligand-mediated apoptosis in renal cell carcinoma. Cancer Res 62: 3093-3099, 2002

13. Han H, Xu B, Hou P, Jiang C, Liu L, Tang M, Yang X, Zhang $Y$ Liu Y: Icaritin sensitizes human glioblastoma cells to TRAILinduced apoptosis. Cell Biochem Biophys 72(2): 533-542, 2015

14. Hayakawa Y, Screpanti V, Yagita H, Grandien A, Ljunggren HG, Smyth MJ, Chambers BJ: NK cell TRAIL eliminates immature dendritic cells in vivo and limits dendritic cell vaccination efficacy. J Immunol 172: 123-129, 2004

15. Hingtgen S, Ren X, Terwilliger E, Classon M, Weissleder R, Shah K: Targeting multiple pathways in gliomas with stem cell and viral delivered S-TRAIL and Temozolomide. Mol Cancer Ther 7: 3575-3585, 2008

16. Janssen EM, Droin NM, Lemmens EE, Pinkoski MJ, Bensinger SJ, Ehst BD, Griffith TS, Green DR, Schoenberger SP: CD4+ T-cell help controls CD8+ T-cell memory via TRAIL-mediated activation-induced cell death. Nature 434: 88-93, 2005

17. Kagawa S, He C, Gu J, Koch P, Rha SJ, Roth JA, Curley SA, Stephens LC, Fang B: Antitumor activity and bystander effects of the tumor necrosis factor-related apoptosis-inducing ligand (TRAIL) gene. Cancer Res 61: 3330-3338, 2001 
18. Kauer TM, Figueiredo JL, Hingtgen S, Shah K: Encapsulated therapeutic stem cells implanted in the tumor resection cavity induce cell death in gliomas. Nat Neurosci 15:197-204, 2012

19. Kim EH, Kim SU, Shin DY, Choi KS: Roscovitine sensitizes glioma cells to TRAIL-mediated apoptosis by downregulation of survivin and XIAP. Oncogene 23: 446-456, 2004

20. Krakstad C, Chekenya M: Survival signalling and apoptosis resistance in glioblastomas: Opportunities for targeted therapeutics. Mol Cancer 9: 135, 2010

21. Kuijlen JM, Bremer E, Mooij JJ, den Dunnen WF, Helfrich W: Review: On TRAIL for malignant glioma therapy? Neuropathol Appl Neurobiol 36: 168-182, 2010

22. Lathia JD, Gallagher J, Myers JT, Li M, Vasanji A, McLendon RE, Hjelmeland AB, Huang AY, Rich JN: Direct in vivo evidence for tumor propagation by glioblastoma cancer stem cells. PLoS One 6: e24807, 2011

23. Menon LG, Kelly K, Yang HW, Kim SK, Black PM, Carroll RS: Human bone marrow-derived mesenchymal stromal cells expressing S-TRAIL as a cellular delivery vehicle for human glioma therapy. Stem Cells 27: 2320-2330, 2009

24. Mohr A, Albarenque SM, Deedigan L, Yu R, Reidy M, Fulda S, Zwacka RM: Targeting of XIAP combined with systemic mesenchymal stem cell-mediated delivery of sTRAIL ligand inhibits metastatic growth of pancreatic carcinoma cells. Stem Cells 28: 2109-2120, 2010

25. Ng CP, Zisman A, Bonavida B: Synergy is achieved by complementation with Apo2L/TRAIL and actinomycin D in Apo2L/TRAIL-mediated apoptosis of prostate cancer cells: role of XIAP in resistance. Prostate 53: 286-299, 2002

26. Nikolovska-Coleska Z, Xu L, Hu Z, Tomita Y, Li P, Roller PP, Wang R, Fang X, Guo R, Zhang M, Lippman ME, Yang D, Wang S: Discovery of embelin as a cell-permeable, smallmolecular weight inhibitor of XIAP through structure-based computational screening of a traditional herbal medicine three-dimensional structure database. J Med Chem 47: 24302440, 2004

27. Ohgaki H, Kleihues P: Population-based studies on incidence, survival rates, and genetic alterations in astrocytic and oligodendroglial gliomas. J Neuropathol Exp Neurol 64: 479489, 2005

28. Panner A, James CD, Berger MS, Pieper RO: mTOR controls FLIPS translation and TRAIL sensitivity in glioblastoma multiforme cells. Mol Cell Biol 25: 8809-8823, 2005

29. Park DM, Rich JN: Biology of glioma cancer stem cells. Mol Cells 28: 7-12, 2009

30. Park SY, Lim SL, Jang HJ, Lee JH, Um JY, Kim SH, Ahn KS, Lee SG: Embelin induces apoptosis in human glioma cells through inactivating NF-kappaB. J Pharmacol Sci 121:192199, 2013

31. Reardon DA, Wen PY: Therapeutic advances in the treatment of glioblastoma: Rationale and potential role of targeted agents. Oncologist 11:152-164, 2006

32. Redjal N, Zhu Y, Shah K: Combination of systemic chemotherapy with local stem cell delivered S-TRAIL in resected brain tumors. Stem Cells 33: 101-110, 2015

33. Rieger J, Naumann U, Glaser T, Ashkenazi A, Weller M: APO2 ligand: A novel lethal weapon against malignant glioma? FEBS Lett 427: 124-128, 1998

34. Roth KA: Caspases, apoptosis, and Alzheimer disease: Causation, correlation, and confusion. J Neuropathol Exp Neurol 60: 829-838, 2001
35. Roth W, Isenmann S, Naumann U, Kugler S, Bahr M, Dichgans J, Ashkenazi A, Weller M: Locoregional Apo2L/TRAIL eradicates intracranial human malignant glioma xenografts in athymic mice in the absence of neurotoxicity. Biochem Biophys Res Commun 265: 479-483, 1999

36. Ruano Y, Mollejo M, Camacho FI, Rodriguez de Lope A, Fiano C, Ribalta T, Martinez P, Hernandez-Moneo JL, Melendez B: Identification of survival-related genes of the phosphatidylinositol 3'-kinase signaling pathway in glioblastoma multiforme. Cancer 112: 1575-1584, 2008

37. Sasportas LS, Kasmieh R, Wakimoto $H$, Hingtgen S, van de Water JA, Mohapatra G, Figueiredo JL, Martuza RL, Weissleder R, Shah K: Assessment of therapeutic efficacy and fate of engineered human mesenchymal stem cells for cancer therapy. Proc Natl Acad Sci U S A 106: 4822-4827, 2009

38. Shah K: Mesenchymal stem cells engineered for cancer therapy. Adv Drug Deliv Rev 64: 739-748, 2012

39. Shah K, Bureau E, Kim DE, Yang K, Tang Y, Weissleder R, Breakefield XO: Glioma therapy and real-time imaging of neural precursor cell migration and tumor regression. Ann Neurol 57: 34-41, 2005

40. Shah $\mathrm{K}$, Tung $\mathrm{CH}$, Yang $\mathrm{K}$, Weissleder $\mathrm{R}$, Breakefield $\mathrm{XO}$ : Inducible release of TRAIL fusion proteins from a proapoptotic form for tumor therapy. Cancer Res 64: 3236-3242, 2004

41. Siegelin MD, Gaiser T, Siegelin Y: The XIAP inhibitor Embelin enhances TRAIL-mediated apoptosis in malignant glioma cells by down-regulation of the short isoform of FLIP. Neurochem Int 55: 423-430, 2009

42. Singh SK, Clarke ID, Terasaki M, Bonn VE, Hawkins C, Squire J, Dirks PB: Identification of a cancer stem cell in human brain tumors. Cancer Res 63: 5821-5828, 2003

43. Stegh AH, Kim H, Bachoo RM, Forloney KL, Zhang J, Schulze H, Park K, Hannon GJ, Yuan J, Louis DN, DePinho RA, Chin L: Bcl2L12 inhibits post-mitochondrial apoptosis signaling in glioblastoma. Genes Dev 21: 98-111, 2007

44. Stupp R, Mason WP, van den Bent MJ, Weller M, Fisher B, Taphoorn MJ, Belanger K, Brandes AA, Marosi C, Bogdahn U, Curschmann J, Janzer RC, Ludwin SK, Gorlia T, Allgeier A, Lacombe D, Cairncross JG, Eisenhauer E, Mirimanoff RO; European Organisation for R, Treatment of Cancer Brain T, Radiotherapy G, National Cancer Institute of Canada Clinical Trials G: Radiotherapy plus concomitant and adjuvant temozolomide for glioblastoma. N Engl J Med 352: 987-996, 2005

45. Tada Y, Brena RM, Hackanson B, Morrison C, Otterson GA, Plass C: Epigenetic modulation of tumor suppressor CCAAT/ enhancer binding protein alpha activity in lung cancer. J Natl Cancer Inst 98: 396-406, 2006

46. Yin D, Ong JM, Hu J, Desmond JC, Kawamata N, Konda BM, Black KL, Koeffler HP: Suberoylanilide hydroxamic acid, a histone deacetylase inhibitor: Effects on gene expression and growth of glioma cells in vitro and in vivo. Clin Cancer Res 13: 1045-1052, 2007

47. Yoshioka $\mathrm{H}$, Shirayoshi $\mathrm{Y}$, Oshimura M: A novel in vitro system for analyzing parental allele-specific histone acetylation in genomic imprinting. J Hum Genet 46: 626-632, 2001

48. Zhang J, Stevens MF, Bradshaw TD: Temozolomide: Mechanisms of action, repair and resistance. Curr Mol Pharmacol 5: 102-114, 2012 